\title{
Characteristics of nanoclay reinforced starch biocomposites through the extrusion process
}

\author{
Heru Suryanto ${ }^{1, *}$, Alfian Widi Rahmawan ${ }^{1}$, Solichin ${ }^{1}$, Rizki Tata Sahana ${ }^{2}$, Uun Yanuhar $^{3}$ \\ ${ }^{1}$ Department of Mechanical Engineering, Faculty of Engineering, State University of Malang, 65145 \\ Malang, Indonesia \\ ${ }^{2}$ Department of Mechanical Engineering, Bachelor Program, State University of Malang, 65145 \\ Malang, Indonesia \\ ${ }^{3}$ Fisheries and Marine Science, Brawijaya University, 65145 Malang, Indonesia
}

\begin{abstract}
The development of materials engineering has led to many significant discoveries one of which is biocomposite with its diverse applications. The addition of reinforcing materials in biopolymers improves the composite properties. This study aimed at investigating the effect of adding nanoclay on the tensile strength, morphology, functional group, and structure of extruded biocomposites with cassava starch matrix. This experimental research involved different concentrations of nanoclay i.e. $0 \%, 2.5 \%, 5 \%, 7.5 \%$. The extrusion process was performed using a single screw extruder at $120^{\circ} \mathrm{C}$. The samples were characterized by tensile testing, XRD, and SEM. The biocomposite reinforced with $5 \%$ nanoclay had the highest tensile strength of $10.8 \mathrm{MPa}$. The highest diffraction peak at $2 \theta$ of $19.4^{\circ}$ appeared in the sample added with $5 \%$ nanoclay. The addition of excessive amounts of nanoclay can hinder the formation of exfoliated structures.
\end{abstract}

\section{Introduction}

The consumption of plastic in Indonesia is increasingly high. Plastics are widely used for packaging materials and other applications due to advantages such as inexpensive, lightweight, and chemically resistant [1]. Plastic is a type of material that is difficult to decompose within a short time of disposal. Petroleum-based plastics, for instance, are synthetic polymers that are so hard to break down; they take approximately more than 50 years to completely degrade in landfills [2].

One viable remedy to solve the problem of plastic waste is through the development of biodegradable plastics/biocomposites which are easily degraded in the environment. Starch is a nanostructured material extracted from tubers such as cassava, which is inexpensive, abundant, renewable, biocompatible, and biodegradable [3]. Cassava starch contains of $12.28 \%$ to $27.38 \%$ amylose and $72.61 \%$ to $87.71 \%$ amylopectin.

\footnotetext{
* Corresponding author: heru.suryanto.ft@um.ac.id
} 
The amylose content affects the mechanical properties of bioplastics, while the amylopectin content gives optimum stickiness [4]. The addition of reinforcing materials in biopolymers improves composite properties such as stiffness and toughness, solubility and UV resistance, thermal and gas barrier properties, and flame retardancy [5]. The use of nanoclay reinforcement affects microstructure and mechanical and thermal properties. The larger the concentration of nanoclay filler is, the higher the elastic modulus will be. The addition of clay ( $<10 \%$ by weight) could increase the tensile strength of biocomposites [67].

The extrusion method is a cooking process in which raw materials are forced through a die by a combination of pressure, heat, and mechanical friction [8]. One of the good points about this method is that it requires a short cycle time, hence cost-effective production. Therefore, this study investigated the characteristics of biocomposites produced by a single screw extrusion process.

\section{Research Method}

\subsection{Apparatus and Materials}

The apparatus consisted of a digital scale, beaker glass, magnetic stirrer, hot plate, thermometer, measuring pipette, spatula, stopwatch, desiccator, macro lens, tensile tester, Fourier Transmitter Infra-Red (FTIR), and X-Ray Diffraction (XRD). The materials used in this research were cassava starch, glycerol, nanoclay, and distilled water.

\subsection{Synthesis of Biocomposites}

The synthesis of biocomposites referred to a study by Mendes et al. [9] in which the bioplastics were made of cassava starch:glycerol: distilled water (40:30:30 wt\%). A mixture of 30 grams of glycerol and 30 grams of distilled water were added with different concentrations of nanoclay i.e. $0 \%, 2.5 \%, 5 \%, 7.5 \%(\mathrm{w} / \mathrm{w})$. Then, the mixture was dispersed into 100 grams of cassava starch to make three variations of the solution with nanoclay, followed by stirring using a magnetic stirrer for 5 minutes. The solution was then heated over a hot plate at $165^{\circ} \mathrm{C}$ for 45 minutes until it changed into gelatine with a temperature of about $70{ }^{\circ} \mathrm{C}$ to $80^{\circ} \mathrm{C}$.

After turning into gelatine, the mixture was fed into a hopper at $120^{\circ} \mathrm{C}$ and held for 10 minutes or 600 seconds before extrusion [10]. After that, the extrusion machine was operated at $5 \mathrm{rpm}$ constantly. The extruded sample was then placed in the oven for 4 hours at $80^{\circ} \mathrm{C}$. After drying, the plastic was stored in a desiccator for analysis.

The synthesis of nanoclay reinforced cassava starch biocomposites was carried out by the single screw extruder of extrusion machine using the dies with an average diameter of $0.279 \mathrm{~mm}$.

\subsection{Mechanical Properties of Biocomposites}

The mechanical properties of extruded cassava starch-nanoclay biocomposites were tested using the "Techno" fiber tensile tester (Techno Lab., Indonesia) with a maximum load of $50 \mathrm{~N}$. The biocomposite was cut into $30 \mathrm{~mm}$ long, placed into the clamp with a length of 10 $\mathrm{mm}$, and stretched with a maximum speed of $0.025 \mathrm{~mm} \cdot \mathrm{s}^{-1}$. The cross-sectional area of biocomposites was determined by photographing the horizontal position. The average of the cross-sectional area of ten samples was measured using the ImageJ $1.51 \mathrm{~K}$ software. 


\subsection{XRD analysis}

XRD analysis was analyze referred to Suryanto et al. [11]. XRD analysis was performed using Diffractometer system from the PanAnalytical X-Pert Pro in ambient temperature and $40 \mathrm{kV}$ and $30 \mathrm{~mA}$. The intensity of diffraction of $\mathrm{CuK} \alpha$ radiation $(\lambda=1.54 \AA)$ was recorded in the range $10^{\circ}$ to $50^{\circ}$.

\subsection{Morphology observation by SEM}

The surface morphology of the biocomposite was observed by the FEI, Inspect-S50 type of Scanning Electron Microscope (SEM) at $10.00 \mathrm{kV}$ after the specimens were coated with a $10 \mathrm{~nm}$ gold layer (sputter coater, SC7-620 Emitech) [12].

\section{Results and Discussion}

The image of the biocomposite product obtained by an extrusion process was shown in Figure 1.

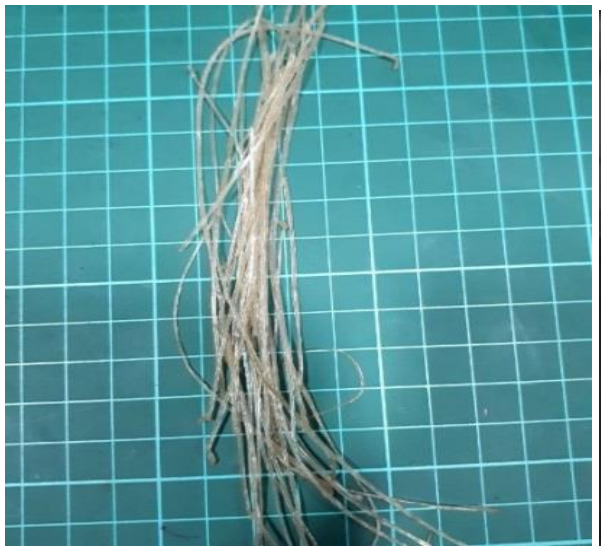

(a)

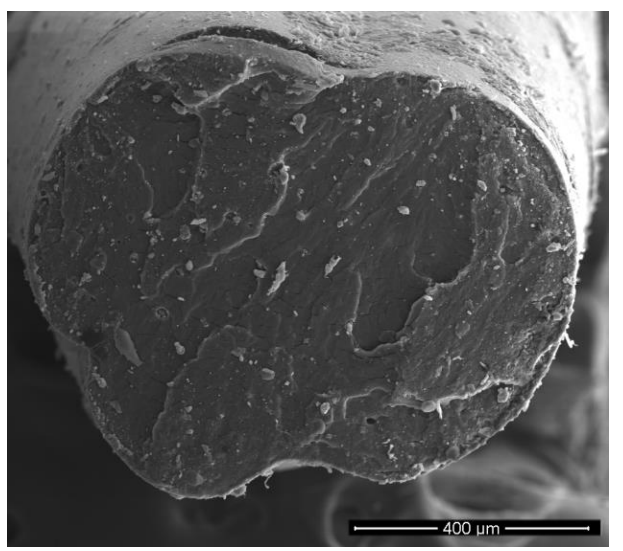

(b)

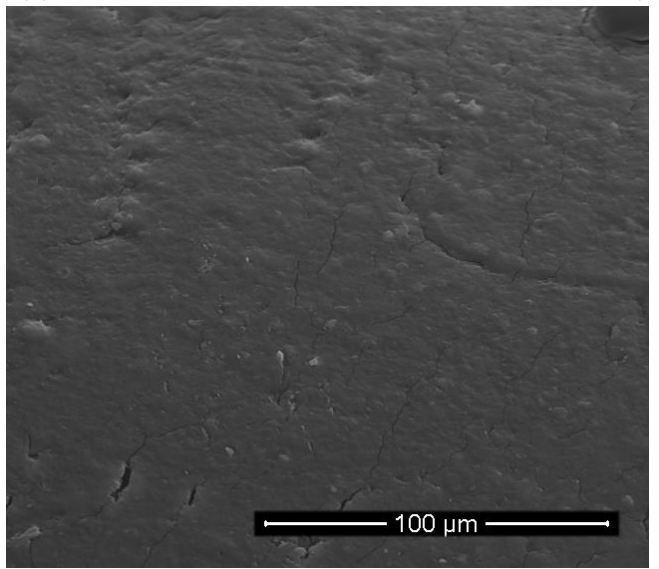

(c) 
Fig. 1. Biocomposite product obtained by an extrusion process (a) Final product (b) image of cross section area by SEM; (c) Image of the circumferential surface area by SEM

The extrusion products have physical properties: neat circles, sometimes little air bubbles was observed. The color is clear but no transparent and slightly brownish. The texture was pliable and slippery (Figure 1a). The surface of both the cross-section area and circumferential surface were smooth and look a little crack (Figure 1b and 1c). The biocomposite formation was influenced by several factors, such as heating conditions (time and temperature) in the extrusion machine, matrix concentration, reinforcement concentration, and plasticiser concentration.

\subsection{Mechanical Properties}

The addition of nanoclay had a significant effect on mechanical properties. The tensile test results showed an increased tensile strength in each sample variant; the addition of $0 \%$, $2.5 \%, 5 \%$, and $7.5 \%(\mathrm{w} / \mathrm{w})$ nanoclay concentrations resulted in biocomposites with a tensile strength of $2.9,7.2,10.8$, and $6.1 \mathrm{MPa}$, respectively.

As shown in Figure 2, the elastic modulus of biocomposites increased along with the addition of $0 \%, 2.5 \%$, and $5 \%(\mathrm{w} / \mathrm{w})$ nanoclay, resulting in biocomposite with an elastic modulus of 1.3, 14.6, and $22.7 \mathrm{MPa}$, respectively. However, after added with $7.5 \%(\mathrm{w} / \mathrm{w})$ nanoclay experienced a decrease in elastic modulus to $17.5 \mathrm{MPa}$.

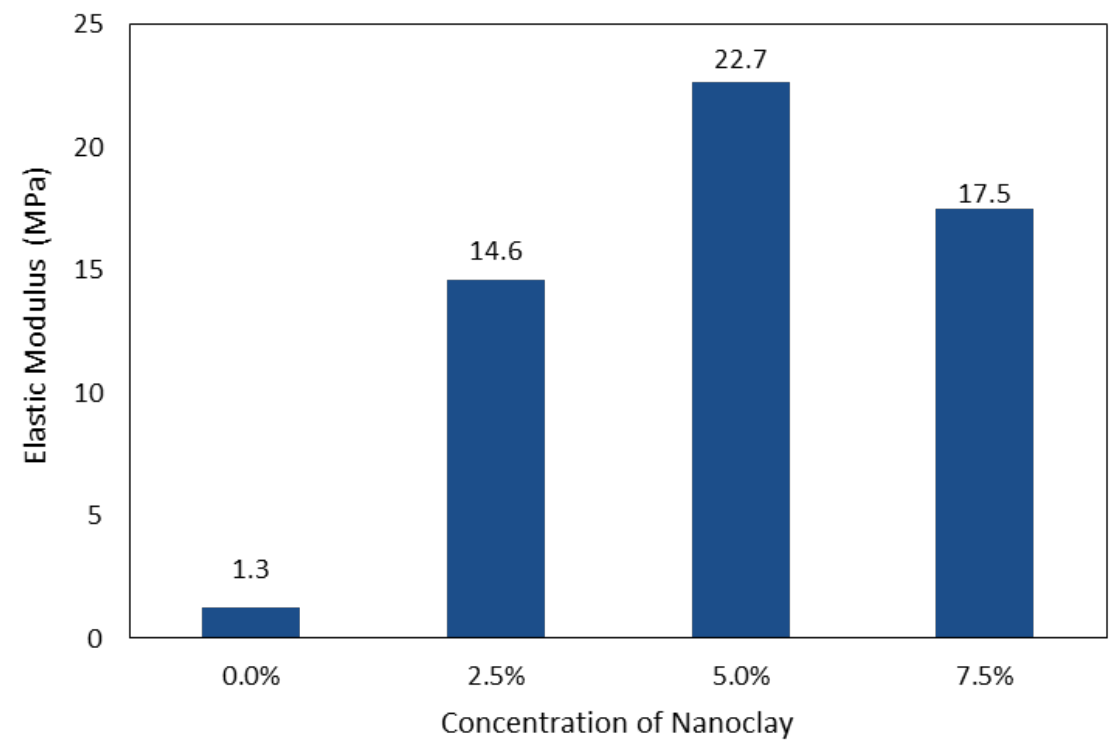

Fig. 2. Effect of nanoclay concentration on the elastic modulus

A determining factor in the improvement of mechanical properties is the dispersion of nanoclay in the matrix [13]. Sari et al [6] further pointed out that the improvement of biocomposite mechanical properties depends on the dispersion and compatibility of nanoclay particles in the polymer matrix. In the nanoclay-polymer composites, synergistic interactions can occur due to the contact between silica and polymer surfaces and the intercalation or exfoliation of montmorillonite layered silicates throughout the polymer matrix.

The decrease in tensile strength occurred when the concentration of nanoclay was $7.5 \%$. It suggested that layered silicates were stacked in the polymer matrix, reducing tensile strength [14]. The decrease in tensile strength was also presumably due to the occurrence of 
agglomeration. Agglomeration was responsible for the presence of cracks and stress concentrations which consequently caused a decrease in tensile strength [15].

\subsection{XRD Analysis}

XRD analysis was performed to examine the structural change of the cassava starch biocomposite matrix reinforced with nanoclay. The XRD diffractogram is presented in Figure 3.

Figure 3 shows biocomposite without nanoclay shows the diffraction peaks at $2 \theta$ of $17.2^{\circ}, 19.4^{\circ}$, and $22.2^{\circ}$. After nanoclay addition, peaks pattern was shifted and peaks at $17.2^{\circ}$ and $22.2^{\circ}$ tends to disappear after the nanoclay addition of $7.5 \%$. The crystalline peaks occurring at around $2 \theta$ of $20^{\circ}$ were due to the precipitation of helical inclusion complexes formed among amylose, plasticisers, and lipids at the time of extrusion [16]. Changes in starch crystal structures occurred because starch granules were exposed to high temperature and shear force during the extrusion process, resulting in reduced particle size [17]. It is in line with Farhat et al. [18] stating that a combination of heat and shear force in the extrusion process led to changes in the crystal structure of starch. The presence of diffraction peaks was attributed to the interaction between the polymer chains and nanoclay with the formation of composites characterized by the intercalated structures and the partial preservation of the layered configuration [19].

Several crystal peaks appeared in the sample with $0 \%$ nanoclay. The crystal structures in biocomposites formed due to cassava starch granules produced by the interlacing between amylose and amylopectin during the gelatinization process [20]. The addition of nanoclay caused changes in the diffraction patterns of biocomposites. The peak shifts and the decrease in intensity indicate that the system was partially exfoliated [21]. The addition of excessive amounts of nanoclay can hinder the formation of exfoliated structures. Such an explanation may be related to the viscosity of the solution. The addition of nanoclay causes the solution to become thicker and agglomerated [22]. 


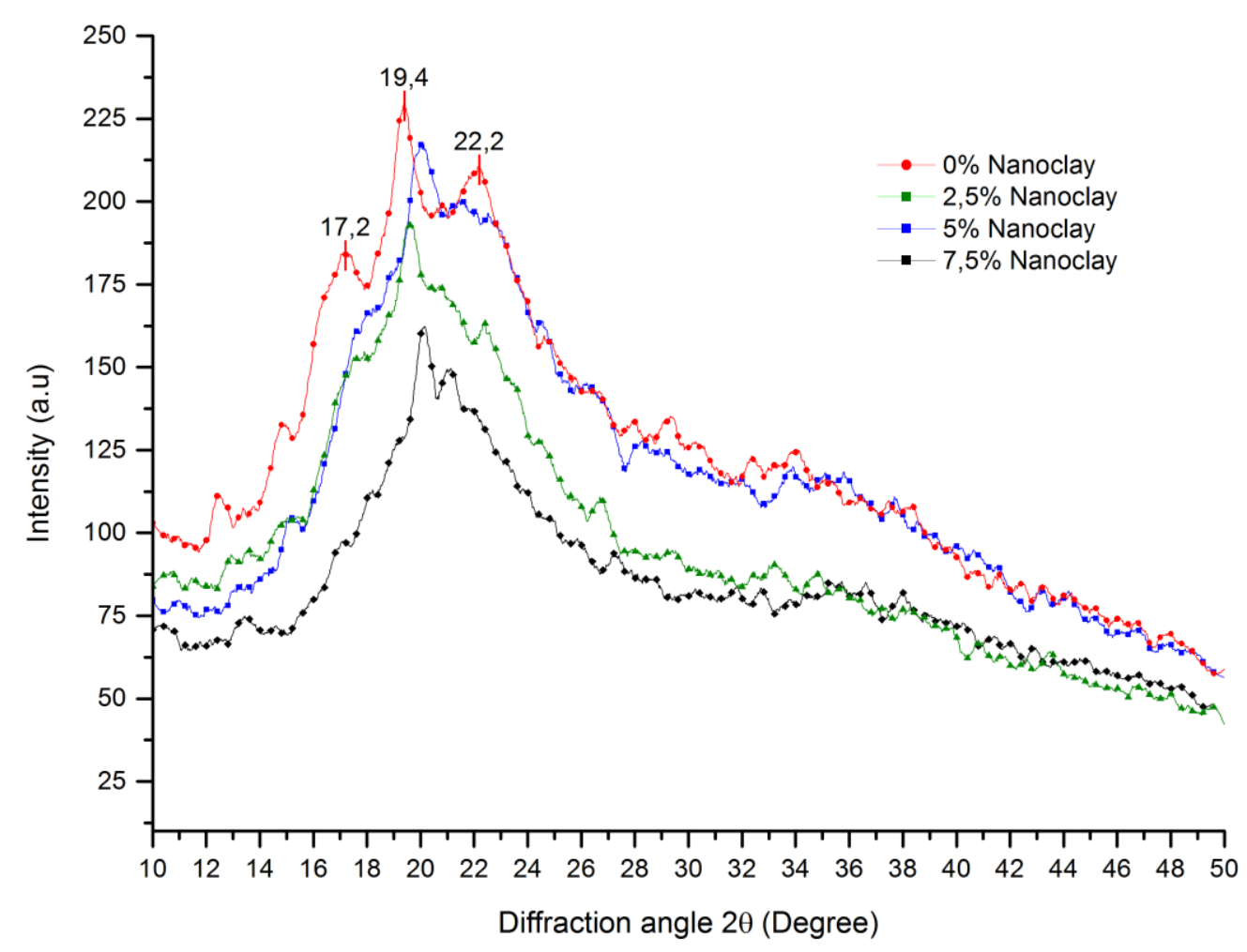

Fig. 3. XRD pattern of cassava starch biocomposites reinforced with various concentrations of nanoclay

\section{Conclusion}

The addition of nanoclay could increase the tensile strength and elastic modulus of the extruded biocomposites. The biocomposite reinforced with 5\% nanoclay had the best mechanical properties, i.e. tensile strength and elastic modulus of $10.8 \mathrm{MPa}$ and $22.7 \mathrm{MPa}$, respectively. The highest diffraction peak at $2 \theta$ of $20.14^{\circ}$ appeared in the sample added with 5\% nanoclay. Among all concentrations of reinforcement, 5\% nanoclay was the most suitable concentration to produce strong biocomposites.

The authors acknowledge to the Ministry of Research, Technology and Higher Education of the Republic of Indonesia under the PDUPT Research Grant 2018 with contract no. 1.3.32/UN.14/LT/2018.

\section{REFERENCES}

1. B. R. Mose and S. M. Maranga, J. Mater. Sci. Eng. B, vol. 1, pp. 239-245 (2011).

2. H. Webb, J. Arnott, R. Crawford, and E. Ivanova, Polymers (Basel)., vol. 5, no. 1, pp. 1-18 (2012).

3. A. S. Abreu, M. Oliveira, A. de Sá, R. M. Rodrigues, M. A. Cerqueira, A. A. Vicente, and A. V Machado, Carbohydr. Polym., vol. 129, pp. 127-34 (2015).

4. Susanti, Jasruddin, and Subaer, J. Sains dan Pendidik. Fis., vol. 11, no. 2, pp. 179-184 
(2015).

5. N. F. Magalhães and C. T. Andrade, Carbohydr. Polym., vol. 75, no. 4, pp. 712-718 (2009).

6. E. P. Sari, S. Rohman, and I. Aziz, J. Kim. Val., vol. 3, no. 2 (2013).

7. H. Santoso and G. Dwigustono, Spectra, vol. 16, no. 1, pp. 59-63 (2015).

8. U. Santoso, T. Murdaningsih, and R. Mudjisihono, J. Teknol. dan Ind. Pangan, vol. 18 , no. 1, pp. 40-46 (2007).

9. J. F. Mendes, R. T. Paschoalin, V. B. Carmona, A. R. S. Neto, A. C. P. Marques, J. M. Marconcini, L. H. C. Mattoso, E. S. Medeiros, and J. E. Oliveira, Carbohydr. Polym., vol. 137, pp. 452-458 (2016).

10. C. de Melo, P. Salomão Garcia, M. Victória Eiras Grossmann, F. Yamashita, L. Henrique Dall, and S. Mali, Braz. Arch. Biol. Technol., vol. 54, no. 6, pp. 1223-1333 (2011).

11. H. Suryanto, P. T. Hutomo, R. Wanjaya, and P. Puspitasari, AIP Int. Proceeding Int. Mech. Eng. Eng. Educ., vol. 30027, pp. 1-5 (2016).

12. H. Suryanto, E. Marsyahyo, Y. Surya Irawan, R. Soenoko, and Aminudin, Int. J. Polym. Sci., vol. 2015, Article Id. 542376, pp. 1-10 (2015).

13. H. Suryanto, S. Jenuardy, D. Kustono, P. Puspitasari, and D. Z. Lubis, Int. Rev. Mech. Eng., vol. 12, no. 3 (in Press) (2018)

14. D. R. Barleany and R. Hartono, in National Seminar Proceeding of Chemistry Engineering, pp. 1-6 (2011).

15. Kusmono, in Proceeding of SNTTM, Palembang (2010).

16. S. Sun, P. Liu, N. Ji, H. Hou, and H. Dong, Food Hydrocoll., vol. 72, pp. 81-89 (2017).

17. D. Song, Y. S. Thio, and Y. Deng, Carbohydr. Polym., vol. 85, no. 1, pp. 208-214 (2011).

18. I. A. Farhat, J. R. Mitchell, J. M. V Blanshard, and W. Derbyshire, Carbohydr. Polym., vol. 30, no. 4, pp. 219-227 (1996).

19. S. Molinaro, M. C. Romero, M. Boaro, A. Sensidoni, C. Lagazio, M. Morris, and J. Kerry, J. Food Eng., vol. 117, no. 1, pp. 113-123 (2013).

20. M. K. S. Monteiro, V. R. L. Oliveira, F. K. G. Santos, E. L. B. Neto, R. H. L. Leite, E. M. M. Aroucha, R. R. Silva, and K. N. O. Silva, Food Res. Int., vol. 105, pp. 637-644 (2018).

21. K. Katerinopoulou, A. Giannakas, K. Grigoriadi, N. M. Barkoula, and A. Ladavos, Carbohydr. Polym., vol. 102, pp. 216-222 (2014).

22. F. Ulfah and I. Nugraha, in Proceeding of SN-KPK, UNS Solo, 2014, pp. 411-423 (2014). 